\title{
The French organisation of mechanical ventilation at home for neuromuscular diseases ${ }^{1}$
}

\author{
P Gajdos MD
}

Service de Réanimation Médicale, Hopital Raymond Poincare, 92380 Garches, France.

In this paper there is an outline of the organisation and the results of domiciliary ventilation for patients with neuromuscular diseases where there are serious respiratory problems, in relation to special facilities that have been made available in France. The clinical and economic benefits are stated, in particular concerning the situation in the greater Paris area.

Keywords: neuromuscular diseases; domiciliary ventilation.

\section{Introduction}

The French experience of domiciliary ventilation began in France at the end of the sixties. By this time many patients who had survived the polio myelitis (APM) outbreak were dependent upon mechanical ventilation (MV) and the problem was how to discharge these patients. With this aim in mind, two non profit making associations, the Association de L'Aide Mutuelle pour la Polio et Personnes Handicapées (ADEP) in Paris and Association Lyonnais pour la Lutte Contre la Polio (ALLP) in Lyon, were created in 1969 by the patients themselves and their relatives with the help of physicians.

During the early years these associations took care of APM patients, and then of patients dependent upon MV because of neuromuscular diseases or patients suffering from chronic obstructive pulmonary disease (COPD).

Progressively other associations were created and by 1990 there were 35 covering all the country. These regional associations are in charge of all technical respiratory assistance equipment: MV, oxygen therapy etc. There aims are: (1) the negotiation with reimbursement agencies; (2) the purchasing of medical equipment; (3) the installation of this equipment at home and if necessary modification of the environment (electrical, system, telephone etc); and (4) a maintenance service and nursing assistance.

\footnotetext{
${ }^{1}$ Paper read at the First European Conference on Domiciliary Ventilation and High Spinal Cord Lesion, in Southport, England, in October 1991.
}

In 1982 a national association, Association Nationale pour le Traitement à Domicile des Insuffisants Respiratoires (ANTADIR +), was established in order to organise wholesale purchasing of equipment, the collection of information on domiciliary respiratory assistance, and collaborative research.

\section{The prescription of mechanical ventilation at home}

The realisation of $\mathrm{MV}$ at home results from a close cooperation between the hospital and the association. The prescription of MV is performed by the physician in charge of the patient, generally in the intensive care unit, and the prescription is a complex process.

First, the criteria for MV at home is a difficult issue. Generally there is an agreement that recognises that when $\mathrm{MV}$ is indicated it is necessary for the medical condition to be stable, ie for the respiratory condition to be at the base line, without acute complications such as infection, and for the neurological disease to be stable or only slowly progressive. On the other hand, respiratory failure has to be defined, and we generally accept one of the following criteria: a vital capacity of less than $20 \%$, a $\mathrm{Pa} 02$ of over $45 \mathrm{mmHg}$, a P02 under $60 \mathrm{mmHg}$, two episodes of acute respiratory failure requiring $\mathrm{MV}$ in the previous history, the impossibility of weaning the patient from MV after an episode of acute respiratory distress.

Secondly, the physician has to discuss the 
principle of MV at home with the patient and his relatives. The return home of a patient is dependent upon technicological support, sometimes 24 hours a day, and includes many problems. It is necessary to be certain that the family will be physically and psychologically able to cope with the situation, and that the home is adequate concerning surfaces, accessibility and installations. Finally, in some cases, it is necessary to find financial or personal support especially when the patient requires the assistance of someone for 24 hours a day. The third step is the choice of the ventilation mode. The medical condition must be considered, but also the patient's wishes, especially concerning the tracheostomy. Intermittent pressure positive ventilation (IPPV) through a nasal mask is now widely used. The great advantage of this technique is that there is no invasion of the airways, albeit also no control of them.

It is ideal for patients who have a normal glottic function and whose degree of respiratory disability allows for an assistance of less than 12 hours a day. But the nasal mask is sometimes badly tolerated. The efficiency of the ventilation may be poor because of air leak between the mask and the face or by the mouth when the patient is sleeping with an open mouth.

Tracheostomy and IPPV are needed if the patient is ventilator dependent for most of the time (ie more than 12-15 hours a day). This technique is also required if there are swallowing disturbances. Furthermore, tracheostomy offers more security and allows the suction of secretions.

External devices may be used, either an iron lung, jackets or cuirass shells. Interesting results are obtained with an inflating abdominal belt in selected cases.

Lastly, when the ventilation mode has been chosen and when the patient is well adapted to the MV, an extensive educational programme for the family members is undertaken. They have to learn how to deal with the machine, to put the mask on properly, or to change the cannula and perform suction of tracheal secretions if the patient has a tracheostomy. They also require to understand the use of a self-inflating resuscitator bag if this should be needed.
The last step in the educational programme, before the definitive discharge, is the organisation of short stays at home for one or two days, with all of the equipment, to ensure that everything is in order.

\section{The material organisation of MV at home}

The regional organisation is in charge of the equipment. For a patient on IPPV via a tracheostomy the Association will deliver one portable positive pressure ventilator with pressure alarms and batteries ( 2 ventilators if the respiratory autonomy is less than 3 hours), one electric suction unit and one portable suction unit, one self-inflating resuscitator bag, and 2 tracheostomy tubes.

The Association takes charge of installing the equipment, checks the home environment and makes any necessary modifications. When the patient is discharged from the hospital a nurse and a technician of the Association help with the installation at home. The nurse will carry on the educational programme. Thereafter there are monthly visits by the nurse for follow up and for the provision of new materials such as cannulae, tubing, nasal masks etc.

The Regional Association is also in charge of the maintenance service. Every patient will have a monthly visit by a technician qualified in mechanics and electronics and fully familiar with the equipment being used. There is a technical emergency service available 24 hours a day, which can come to the patient's home very quickly. In the Paris area, a tele-alarm system is available, organised by the 'Fondation Garches', the Regional Association and the Medical First Aid Service. The tele-alarm is connected to the telephone. Intercom contact with an operator may be established 24 hours a day by the patient or a family member by pressing a device hanging around the neck of the patient. The operator room is located at the first medical aid service so that the operator can give appropriate advice and can send out a medical emergency team if necessary.

The medical follow up is performed by the family physician. Every 6 or 12 months a check-up is made in the hospital including a 
fibre optic check of the trachea and an adjustment of the MV if needed.

All this organisation requires good familial and social conditions. For patients who do not have such conditions, and therefore could not return home, the Regional Association of Paris has developed two independent living centres. These centres consist of 12 or 15 units in a residential complex. In these buildings, each resident has an individual studio with kitchenette and bathroom, and there is also a common area for social activities. Nurses and physiotherapists work full time for the residents so that the security of a ventilator dependent patient is ensured. Medical supervision is carried out by a local physician along with a specialist in intensive care.

\section{Financial aspect}

The Regional Association negotiates with the 'securité sociale' for suitable reimbursement per day covering all expenses for different well defined modes of assistance. These rates are very low in comparison with the cost of the same treatment in hospital. The reimbursement rates in the greater Paris area is given in Table $\mathrm{I}$.

\section{Results and conclusion}

The organisation is cost saving and allows the return home of a great number of
Table I Reimbursement rate of domiciliary ventilation in the greater Paris area (1990)

\begin{tabular}{lc}
\hline & $\begin{array}{c}\text { Reimbursement } \\
\text { rate per day }\end{array}$ \\
\hline MV via a tracheotomy & $60 \mathrm{FF}$ \\
MV via a tracheotomy with & $93 \mathrm{FF}$ \\
oxygen & $49 \mathrm{FF}$ \\
MV via a nasal mask & $75 \mathrm{FF}$ \\
$\begin{array}{l}\text { MVygen a nasal mask with } \\
\text { Living centre }\end{array}$ & $1278 \mathrm{FF}$ \\
\hline
\end{tabular}

$\mathrm{MV}=$ mechanical ventilation

$\mathrm{FF}=$ French franc

patients. It is also efficient in term of clinical result.

For ADEP, the organisation of the greater Paris area covering about eleven million inhabitants, the total number of patients treated in September 1991 was 2300, and among them 164 were on MV for neuromuscular diseases: 96 were ventilated by IPPV via a tracheostomy and 67 via a nasal mask. One patient used an iron lung. In 1983 the survival rate after 5 years for the patient treated by ALLP $^{1}$ was $95 \%$ for poliomyelitis $(n=41)$ and $62 \%$ for myopathy $(n=11)$. In 1984 the survival rate for patients with neuromuscular diseases treated by $\mathrm{ADEP}^{2}$ was $80 \%(n=110)$.

\section{References}

1 Robert D. Gerard M. Leger P. Buffat J, Sennequin J. Holzapfel L et al (1983) La ventilation mécanique à domicile définitive par trachéotomie de l’insuffisant respiratoire chronique. Rev Fr Mal Resp 11: 923-936.

2 Goulon M, Raphael JC, Brunel D, Chastang C (1984) Ventilation artificiells à domicile des patients présentant une atteinte respiratoire d'origine neurologique. Bull Acad Nat Med (Paris) 168: 313-314. 